\title{
Impacts of moose (Alces alces) at different simulated densities on eco-morphological groups of soil mesofauna
}

\author{
Emanuela Elia, Alessandro Bianchi, Paola Ferrazzi, Roger Bergström, Kjell Danell, \\ Dan Chamberlain \& Inga-Lill Persson
}

\begin{abstract}
Elia, E., Bianchi, A., Ferrazzi, P., Bergström, R., Danell, K., Chamberlain, D. \& Persson, I.-L. 2010: Impacts of moose (Alces alces) at different simulated densities on eco-morphological groups of soil mesofauna. - Entomol Fennica 21: $168-180$.
\end{abstract}

We experimentally tested the impact of browsing, defecation and urination corresponding to four different levels of moose population density on abundance and number of eco-morphological groups of soil mesofauna in a Swedish boreal forest. The study was carried out in three fenced exclosures representing different levels of productivity (from nutrient-rich to nutrient-poor). Moose impact on soil communities was evaluated by analysing abundance, richness and diversity of mesofaunal groups, and by means of a multi-taxa index based on ecomorphological groups, the Biological Soil Quality index (QBS). There was a negative impact of high moose densities on the abundance and richness of soil mesofauna. Furthermore, low-moderate moose densities had a positive impact on abundance and number of eco-morphological groups. We conclude that moose can have a large impact on soil-living mesofauna, and therefore probably soil decomposition processes and biological soil quality, in young boreal forest stands.

E. Elia, A. Bianchi \& P. Ferrazzi, Di.Va.P.R.A. - Entomologia e Zoologia applicate all' Ambiente "Carlo Vidano", V. Leonardo da Vinci 44, 10045 Grugliasco (To), Italy; Corresponding author's e-mail: emanuela.elia@unito.it

R. Bergström, Forestry Research Institute of Sweden, Uppsala Science Park, SE75183 Uppsala, Sweden \& Department of Wildlife, Fish and Environmental Studies, Swedish University of Agricultural Sciences, SE-90183 Umeå, Sweden K. Danell \& I.-L. Persson, Department of Wildlife, Fish and Environmental Studies, Swedish University of Agricultural Sciences, SE-90183 Umeå, Sweden

D. Chamberlain, Dipartimento di Biologia Animale e dell'Uomo, Universita di Torino, Via Academia 13, Torino 10123, Italy

Received 2 April 2010, accepted 23 June 2010

\section{Introduction}

The selective feeding of large mammalian herbivores can significantly change plant community structure, species composition and productivity (e.g. Pastor \& Naiman 1992, Hobbs 1996, Au- gustine \& McNaughton 1998, Danell et al. 2006). These changes can further indirectly affect the abundance and diversity of animal groups at different trophic levels and fundamental ecosystem processes such as the quantity and quality of litterfall and soil decomposition and mineraliza- 
tion (Pastor \& Naiman 1992, Augustine \& McNaughton 1998, Côte et al. 2004, Danell et al. 2006, Suominen et al. 2008).

The moose (Alces alces Linnaeus) has been shown to have a significant impact on the ecosystem of boreal forests, especially at higher population densities (e.g. Pastor \& Naiman 1992, Danell et al. 1994, Persson et al. 2007, Suominen et al. 2008). The population densities in some areas of Sweden are among the highest in the world and constitute densities probably not experienced in post-glacial times (Cederlund \& Bergström 1996). Moose mainly affect the ecosystem by selective browsing in the tree and shrub-layers in young forest stands. Young trees and shrubs make up a major part of their diet both in summer and winter (Cederlund et al. 1980, Bergström \& Hjeljord 1987), and moose browsing at high population densities generally results in decreased tree height, a more open tree canopy, and increased dominance of less preferred species (McInnes et al. 1992, Pastor \& Naiman 1992, Persson et al. 2007).

The changes in the tree and shrub layers have further been shown to result in lower litter production and subsequent lower soil nutrient levels at higher moose densities (Pastor \& Naiman 1992, Persson et al. 2005a), which can result in lower decomposition rates and soil nutrient cycling (Pastor \& Naiman 1992, Pastor et al. 1993). Browsed trees can also be expected to reduce allocation of resources to root growth (Côte et al. 2004) and thus affect mycorrhizal fungi. However, such impacts on the ecosystem also strongly depend on moose population density, and moose at lower densities can even have positive effects on the above processes (Pastor \& Naiman 1992, Persson et al. 2005a,b, 2007). For example, moose also deposit faeces and urine, which contain easily available soil nutrients which may have important effects on vegetation and soil microbial biomass (as demonstrated experimentally in reindeer Rangifer tarandus; Van der Wal et al. 2004), but the effects of selective feeding have been shown to be more important at larger spatial and temporal scales (Pastor \& Naiman 1992).

The soil fauna is important in maintaining ecosystem functioning, and fundamental soil processes may be maintained or enhanced by conserving the biological diversity of soil ecosys- tems (Stork \& Eggleton 1992, Filser et al. 1995, Bengtsson et al. 2000). Furthermore, much of the biodiversity of forest ecosystems resides in soil (Behan-Pelletier \& Newton 1999). Soil mesofauna constitute an important animal group in the boreal forest in terms of ecosystem processes such as decomposition of organic matter, nutrient mineralisation and plant growth (Liiri et al. 2002). They are linked with catalysis of organic matter decomposition and nutrient cycling, they have an important regulatory role in soil microbial processes and community structure, soil structure and hydrologic fluxes, and they accelerate plant litter decomposition through interactions with the microflora (Moore \& Walter 1988, Wardle et al. 1999).

Soil quality has been defined as "the functionality of a soil in its own environment, the capability to sustain plants and animal productivity, and to maintain or improve the air and water quality" (Karlen et al. 1997). Certain groups of soil invertebrates are sensitive to variations in the terrestrial environment, such as nutrient levels and pollution, and thus are good indicators of changes in soil quality (Van Straalen 1997, Ponge et al. 2003). Therefore, soil zoocoenoses have been recognised as important descriptors of environmental quality (Parisi 2001, Parisi et al. 2005), and some soil invertebrates in particular are considered important bioindicators of soil quality. The results from research on the direct and indirect interactions between moose, the plant community and soil decomposition and nutrient cycling (e.g. Pastor et al. 1993, Persson et al. 2007, Persson et al.2009) indicate that moose have a strong potential to affect abundance and diversity of soil-living organisms. However, soil mesofaunal sensitivity to impacts of moose, or any other native forest-living large herbivore, has as far as we know never been examined, although research on impacts of non-native herbivores has shown some significant impacts on soil mesofauna in addition to other measures of soil quality (Wardle et al. 2001).

In order to examine moose impacts on soil mesofauna, we experimentally tested how simulated browsing, defecation and urination corresponding to four different population densities of moose (including the scenario with no moose present) affected various measures of soil meso- 
fauna abundance, richness and diversity in sites ranging from very nutrient-poor to nutrient-rich in a Swedish boreal forest. We used an experimental set-up which has been extensively studied to examine moose impact on the boreal ecosystem, particularly on primary productivity and litterfall (Persson et al. 2005a,b, 2007). Based on previous findings from the experiment (as summarised above), we predicted that high levels of simulated moose density would have a negative impact on soil mesofauna, whereas low-moderate moose densities would have a positive impact. We further tested if abundance, richness and diversity of soil mesofauna groups were correlated with litter production. Litter is an important factor regulating soil mesofauna (Blair et al. 1988, Eaton et al. 2004) and quality and quantity of detritus have been shown to affect mesofauna densities (Seasted 1984, Takeda 1987). The decrease in litterfall with increasing moose densities previously documented from the experimental set-up (Persson et al. 2005a) suggests that abundance and diversity of soil mesofauna should be positively correlated with litter production.

\section{Materials and methods}

\subsection{Study sites}

The study was performed in an established experimental field set-up in the middle boreal zone of northern coastal Sweden situated 50-90 km N and NW of Umeå $\left(63^{\circ} 50^{\prime} \mathrm{N}, 20^{\circ} 18^{\prime} \mathrm{E}\right)$, with fenced $70 \times 70 \mathrm{~m}$ exclosures (Fig. 1) situated in young forests dominated by Scots pine (Pinus sylvestris L.) and birch (Betula pubescens Ehrh. and $B$. pendula Roth.) with more sparsely occurring aspen (Populus tremula L.), rowan (Sorbus aucuparia L.) and willows (Salix spp.). The sites were chosen to represent the full range of the habitat productivity gradient in the study area: 1) a nutrient-poor lichen-rich pine heath (Lögdåberget); 2) a site dominated by bilberry (Vaccinium myrtillus L.) and lingonberry ( $V$. vitis-idaea L.) in the shrub layer (Ralberget), and a mixture of birch, pine and Norway spruce (Picea abies (L.)) in the tree layer; and, 3) a very nutrient-rich site with a high intermixture of deciduous trees, ferns and forbs (Mörtsjöstavaren). For conve-
$70 \mathrm{~m}$

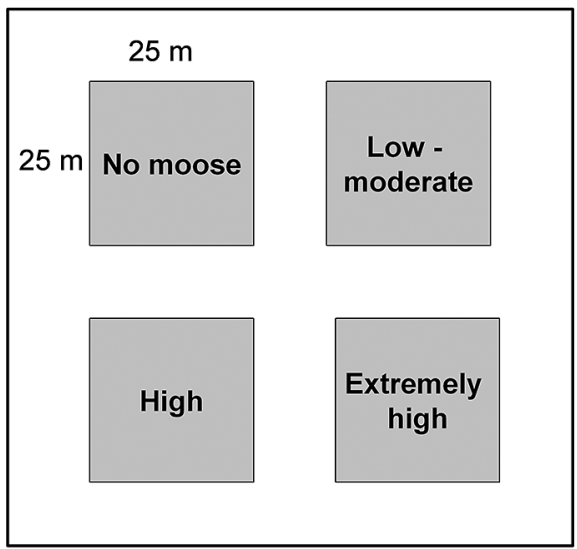

$70 \mathrm{~m}$

Fig. 1. The experimental design with fenced exclosures $\left(4,900 \mathrm{~m}^{2}\right)$, one exclosure per each of three habitat types (i.e. sites). Inside fenced exclosures we simulated browsing, defecation and urination corresponding to 3 different moose densities in treatment plots of $25 \times 25 \mathrm{~m}$. One plot was left untouched to represent no moose, and constituted the statistical control plot. There were buffer zones of $5 \mathrm{~m}$ between treatment plots as well as between treatment plots and the fence. Low-moderate moose density corresponds to 1 moose per $\mathrm{km}^{2}$ in winter, high to 3 per $\mathrm{km}^{2}$ and extremely high to 5 per $\mathrm{km}^{2}$.

nience, we use the term 'habitat type' to refer to the productivity gradient.

\subsection{Experimental design}

Full details of the experimental set-up, and the protocols to simulate browsing, defacation and urination have been published elsewhere (Persson 2003, Persson et al. 2005a), so we provide only a summary here.

In each exclosure, browsing, defecation and urination corresponding to 4 levels of moose population density, from no moose present (the statistical control) to one of the highest local densities experienced in Sweden ( 5 moose per $\mathrm{km}^{2}$ in winter density) had been simulated since 1999 in plots of $25 \times 25 \mathrm{~m}$ within each exclosure (Fig. 1). Protocols to simulate moose browsing were developed to match as closely as possible known behaviour, diet and intake rates of moose in the area (Persson et al. 2000, Persson et al. 2005a, 
Table 1. - a. Soil mesofaunal groups (based on Parisi et al. 2001) used in the analysis. - b. Abundance (individuals per $3,000 \mathrm{~cm}^{3}$ soil volume unit) for each relevant eco-morphological group identified, shown per each exclosure subject to different simulated moose densities and nutrient levels. $-c$. Total abundances (from part b) as well as diversity indices and the Biological Soil Quality index (QBS), shown per each exclosure subject to different simulated moose densities and nutrient levels.

(a) Eco-morphological groups

Group name Characteristics (where relevant)

Collembola1

Collembola 2

Collembola 3

Collembola 4

Collembola 5

Collembola 6

Collembola 7

Cicada

OHemip

Thysanoptera

Coleoptera1

Coleoptera2

Formicidae

OHymen

DipL

Hol-L

Hol-A

Protura

Diplura

Opiliones

Aran-L

Aran-S

Acarina

Chil-L

Chil-S
Epigeous forms, complex pigmentation, well developed appendages

Epigeous forms not associated with grass, trees, shrubs

Small, modest pigmentation, average appendage development,

Hemi-edaphic, not elongated appendages, cuticle pigmented

Hemi-edaphic, reduced ommatidia, scarcely developed appendages

Eu-edaphic, unpigmentated, furca reduced, ommatidia reduced

Eu-edaphic, unpigmentated, furca absent, short appendages

Larvae

Other Hemiptera (epigeous or root-feeding forms)

Adults, epigeous, $>2 \mathrm{~mm}$

Adults, epigeous, $<2 \mathrm{~mm}$

Other Hymenoptera

Diptera larvae

Other holometabolous insects, larvae

Other holometabolous insects, adults

Araneae $>5 \mathrm{~mm}$

Araneae, $<5 \mathrm{~mm}$, scarcely pigmented

Chilopoda $>5 \mathrm{~mm}$, well developed legs

Chilopoda $<5 \mathrm{~mm}$

(b) Soil mesofauna abundance

\begin{tabular}{|c|c|c|c|c|c|c|c|c|c|c|c|c|}
\hline Moose dens.\# & 0 & 1 & 3 & 5 & 0 & 1 & 3 & 5 & 0 & 1 & 3 & 5 \\
\hline Productivity \$ & $\mathrm{L}$ & $\mathrm{L}$ & $\mathrm{L}$ & $\mathrm{L}$ & $M$ & $M$ & $M$ & $\mathrm{M}$ & $\mathrm{H}$ & $\mathrm{H}$ & $\mathrm{H}$ & $\mathrm{H}$ \\
\hline Collembola1 & 2 & 0 & 24 & 11 & 0 & 6 & 12 & 13 & 21 & 1 & 12 & 7 \\
\hline Collembola2 & 11 & 8 & 28 & 4 & 12 & 15 & 0 & 4 & 2 & 38 & 24 & 0 \\
\hline Collembola3 & 16 & 23 & 6 & 4 & 85 & 23 & 57 & 21 & 82 & 61 & 11 & 13 \\
\hline Collembola4 & 17 & 24 & 22 & 5 & 4 & 1 & 3 & 25 & 25 & 45 & 14 & 24 \\
\hline Collembola5 & 12 & 58 & 6 & 11 & 37 & 8 & 1 & 15 & 24 & 41 & 44 & 48 \\
\hline Collembola6 & 3 & 7 & 26 & 7 & 39 & 156 & 22 & 8 & 15 & 46 & 91 & 74 \\
\hline Collembola7 & 5 & 9 & 15 & 0 & 15 & 33 & 18 & 4 & 89 & 211 & 49 & 14 \\
\hline Cicada & 0 & 1 & 0 & 0 & 0 & 1 & 0 & 0 & 2 & 3 & 0 & 0 \\
\hline Ohemip & 1 & 1 & 1 & 1 & 2 & 9 & 3 & 5 & 5 & 5 & 3 & 0 \\
\hline Thysanoptera & 0 & 0 & 0 & 0 & 0 & 1 & 1 & 0 & 2 & 2 & 0 & 0 \\
\hline Coleoptera1 & 0 & 1 & 1 & 0 & 0 & 2 & 0 & 0 & 0 & 0 & 0 & 2 \\
\hline Coleoptera2 & 0 & 0 & 0 & 0 & 3 & 0 & 0 & 3 & 1 & 2 & 0 & 0 \\
\hline Formicidae & 3 & 0 & 0 & 0 & 2 & 13 & 0 & 0 & 7 & 1 & 1 & 5 \\
\hline Ohymen & 1 & 1 & 0 & 0 & 0 & 0 & 0 & 0 & 1 & 0 & 0 & 0 \\
\hline DipL & 4 & 3 & 8 & 1 & 7 & 12 & 1 & 1 & 0 & 18 & 12 & 19 \\
\hline Hol-L & 4 & 1 & 19 & 6 & 13 & 26 & 55 & 4 & 21 & 16 & 26 & 7 \\
\hline Hol-A & 0 & 3 & 1 & 0 & 6 & 1 & 0 & 1 & 0 & 0 & 1 & 1 \\
\hline Protura & 0 & 0 & 0 & 0 & 3 & 2 & 1 & 0 & 0 & 1 & 1 & 0 \\
\hline Diplura & 0 & 0 & 0 & 0 & 0 & 1 & 0 & 0 & 1 & 3 & 2 & 0 \\
\hline
\end{tabular}


Table 1, continued

\begin{tabular}{lrrrrrrrrrrrr} 
Opiliones & 0 & 0 & 0 & 0 & 3 & 1 & 0 & 0 & 1 & 0 & 1 & 0 \\
Aran-L & 0 & 0 & 0 & 0 & 0 & 0 & 0 & 0 & 1 & 1 & 0 & 0 \\
Aran-S & 0 & 0 & 2 & 0 & 0 & 1 & 1 & 3 & 1 & 4 & 0 & 0 \\
Acarina & 623 & 797 & 419 & 349 & 734 & 112 & 384 & 164 & 928 & 687 & 728 & 512 \\
Chil-L & 1 & 0 & 0 & 0 & 0 & 0 & 1 & 0 & 1 & 1 & 1 & 0 \\
Chil-S & 1 & 1 & 0 & 0 & 0 & 0 & 0 & 0 & 0 & 0 & 0 & 0 \\
\hline
\end{tabular}

(c) Total abundance, total taxa and derived indices

\begin{tabular}{lrrrrrrrrrrrr}
\hline Moose dens.\# & 0 & 1 & 3 & 5 & 0 & 1 & 3 & 5 & 0 & 1 & 3 & 5 \\
Productivity \$ & $\mathrm{L}$ & $\mathrm{L}$ & $\mathrm{L}$ & $\mathrm{L}$ & $\mathrm{M}$ & $\mathrm{M}$ & $\mathrm{M}$ & $\mathrm{M}$ & $\mathrm{H}$ & $\mathrm{H}$ & $\mathrm{H}$ & $\mathrm{H}$ \\
Tot. abundance & 704 & 936 & 578 & 399 & 965 & 424 & 560 & 271 & 1,230 & 1,187 & 1,021 & 726 \\
Total taxa & 15 & 15 & 14 & 10 & 15 & 20 & 14 & 14 & 20 & 20 & 17 & 12 \\
Menhinick & 0.57 & 0.49 & 0.58 & 0.50 & 0.48 & 0.97 & 0.59 & 0.85 & 0.57 & 0.58 & 0.53 & 0.45 \\
Margalef & 5.27 & 5.05 & 5.07 & 3.84 & 5.03 & 7.61 & 5.09 & 5.75 & 6.47 & 6.51 & 5.65 & 4.19 \\
Simpson & 0.78 & 0.73 & 0.54 & 0.77 & 0.59 & 0.22 & 0.49 & 0.39 & 0.58 & 0.37 & 0.52 & 0.51 \\
Shannon & 0.61 & 0.69 & 1.19 & 0.63 & 1.02 & 1.94 & 1.16 & 1.53 & 1.06 & 1.50 & 1.19 & 0.41 \\
QBS & 97 & 94 & 68 & 51 & 102 & 134 & 97 & 82 & 119 & 138 & 127 & 67 \\
\hline
\end{tabular}

\# Individuals per $\mathrm{km}^{2}$

$\$ \mathrm{~L}=$ low, $\mathrm{M}=$ moderate and $\mathrm{H}=$ high

2007), which varied according to plant species and season. The removal of biomass to simulate moose browsing in the treatment plots was calculated for the different moose densities based on an estimated daily food intake of moose of $5 \mathrm{~kg}$ dry mass in winter and $10 \mathrm{~kg}$ in summer (Persson et al. 2000), and a winter and summer season of 180 days each. The species composition of food plants in the harvest was based on the composition of moose diet in boreal habitats in Sweden (Cederlund et al. 1980, Bergström \& Hjeljord 1987) and included trees (pine, birch, aspen, willow and rowan) and shrubs (bilberry, heather Calluna vulgaris (L.) Hull and fireweed Epilobium angustifolium L.).

Browsing was simulated by clipping living shoots from a range of known food plants at appropriate heights and in appropriate dietary proportions. The height at which vegetation was sampled was also varied according to season (vegetation was usually under snow up to a height of $50 \mathrm{~cm}$ in winter). The mass of all removed plant material was measured each time to $0.1 \mathrm{~g}$ precision. Clipping was carried out until the estimated biomass for the moose density in question was obtained. All removed plant material was deposited outside the study area. In the growing season (May through October) clippings were taken once a month. For winter, when plants are dor- mant, clippings for the whole winter were taken in April before the growing season started. We also added natural moose dung (collected at a nearby moose farm where moose were fed a natural diet; Nyberg \& Persson 2002) and urine (artificially made by dissolving urea in water, the concentration of which was based on moose studies in North America; Persson 2003) in proportion to the simulated moose density.

\subsection{Soil sampling}

In 2004, after 5 years of experimental treatment, soil samples were collected. In the mid-growing season (July), 3 soil cores per treatment were randomly collected within each exclosure. Sampling was carried out by driving iron cores into the soil in dry weather. Each soil core was square in cross-section $10 \mathrm{~cm}$ deep and $100 \mathrm{~cm}^{2}$ in area; thus $1,000 \mathrm{~cm}^{3}$ soil was collected per sample, and then used for extracting soil arthropods via modified Berlese-Tullgren funnels. Data on litter fall were available from a previous study (Persson et al. 2005a), where we collected plant litter from the tree and shrub layers for one year (i.e. one litter cycle). Thirty traps (plastic pots of height 35 $\mathrm{cm}$, top diameter $50 \mathrm{~cm}$ and bottom diameter 35 $\mathrm{cm})$ were placed in each treatment plot in all 
Table 2. Test statistics for the ANOVA models of the effects of treatment (i.e. level of simulated moose density) and habitat type (block factor) on total no. of mesofauna individuals (Tot. mesofauna), total no. of eco-morphological groups (Tot. groups), total no. of Collembola and total no. of Acari sampled per treatment area on a 3,000 $\mathrm{cm}^{3}$ soil volume unit, as well as the Biological Soil Quality index (QBS). F-values, degrees of freedom and $p$-values are presented for the full two-way ANOVA, and for treatment and site effects separately.

\begin{tabular}{lcccc}
\hline Variable tested & Statistic & $\begin{array}{c}\text { Full model } \\
d f=5,6\end{array}$ & $\begin{array}{c}\text { Treatment } \\
d f=3,6\end{array}$ & $\begin{array}{c}\text { Habitat type } \\
d f=2,6\end{array}$ \\
\hline Tot. mesofauna & $F$ & 7.08 & 5.20 & 9.91 \\
Tot. groups & $p$ & $0.02^{*}$ & $0.04^{*}$ & $0.01^{*}$ \\
QBS & $F$ & 6.00 & 6.97 & 4.54 \\
Tot. Collembola & $p$ & $0.02^{*}$ & $0.02^{*}$ & 0.06 \\
Tot. Acarina & $F$ & 9.17 & 9.85 & 8.15 \\
& $F$ & $0.01^{*}$ & $0.01^{*}$ & $0.02^{*}$ \\
& $p$ & 9.04 & 5.51 & 14.35 \\
& $F$ & $0.009^{*}$ & $0.04^{*}$ & $0.005^{*}$ \\
& $p$ & 3.51 & 2.93 & 4.38 \\
\end{tabular}

${ }^{*} p$ values reporting statistical significance $(p<0.05)$ according to ANOVA.

exclosures, for a total of 120 per exclosure. The traps were emptied monthly during the growing season and as soon as possible after snowmelt in spring. The litter was dried at $40^{\circ} \mathrm{C}$, and production of litter ( $\mathrm{g}$ dry mass per $\mathrm{m}^{2}$ per year) for each exclosure and treatment plot was calculated.

\subsection{Soil mesofauna descriptors}

Arthropods were counted by means of microscopic observations and classified according to the biological form approach (Sacchi \& Testard 1971). Biological forms were separated into groups having homogeneous morphological characters (listed in Table 1), according to the classification of Parisi et al. (2005). Total mesofauna abundance, number of eco-morphological groups and total number of Collembola and Acarina were counted by pooling together the three samples collected in every treatment area.

In addition, we consider an indicator of biological soil quality, the Biological Soil Quality index (QBS; Parisi 2001, Parisi et al. 2005). The QBS is intended to assess soil conditions via analysis of microarthropod communities and is based on the concept that a higher soil quality is reflected by a higher number of microarthropod groups well adapted to the soil habitat (Parisi et al. 2005). The QBS takes into account microarthropod adaptation to the soil by giving a nu- meric value to each biological form (sensu Sacchi $\&$ Testard 1971) in relation to its degree of adaptation to the edaphic environment, e.g. reduction or loss of pigmentation and visual apparatus, streamlined body form and reduced appendages. Higher scores indicate a greater level of adaptation to soil life for a given mesofaunal group. For example, groups such as Symphyla, Acarina and Protura have a value of 20, Diptera larvae 10 . Other taxa, such as Collembola, encompass a number of groups with a range of scores (from 1 to 20) reflecting their diversity of adaptation to the edaphic environment (further details given in Parisi et al. 2005). The QBS index is the sum of the scores across the defined groups.

Given the importance of the biodiversity of soil systems to fundamental soil processes (Stork \& Eggleton 1992, Filser et al. 1995, Bengtsson et al. 2000), we also expect impacts of simulated moose density on diversity measures. The ecomorphological groups classified by the QBS index were therefore also used to calculate indices describing different aspects of soil fauna diversity (Magurran 2004): species richness - Menhinick (Menhinick 1964) and Margalef (Margalef 1957); dominance - Simpson (Simpson 1949); and, diversity - Shannon-Weaver (Shannon \& Weaver 1948). All indices were calculated as a single value for each replication of treatment (i.e. by pooling together counts from the three treatment cores collected in every treatment area). 


\subsection{Statistics}

Effects of different levels of simulated moose population density on soil mesofauna abundance (number of individuals per treatment), group richness (number of groups per treatment, as defined in Table 1), diversity (Menhinick, Margalef, Simpson and Shannon-Weaver) and QBS index were analyzed using analysis of variance (ANOVA) models with level of simulated moose density as the nominal experimental factor $(N=$ 4) and site (i.e, habitat type) as a block factor. Effects on abundance were first analyzed for all soil mesofauna pooled and thereafter for the dominant groups Collembola and Acarina separately. When the ANOVA was significant $(p<0.05)$, post-hoc Tukey tests were carried out to show which specific treatments differed from each other. Relationships between litter production and mesofauna abundance, richness, diversity and QBS index were analysed using linear regression.

\section{Results}

A total of 9,001 individuals of soil invertebrates were extracted and classified according to the groups in Table 1. The ANOVA models showed that total number of organisms (i.e. total abundance) and the total number of eco-morphological groups sampled per treatment area on a 3,000 $\mathrm{cm}^{3}$ soil volume, as well the QBS index, were significantly affected by both simulated moose density (treatment) and habitat type (Table 2).

The total number of groups per treatment and the QBS index showed the same response pattern: the highest value in the plots where we had simulated low-moderate moose density $\left(1\right.$ per $\mathrm{km}^{2}$ in winter density), and the lowest value in the plots where we had simulated a very high moose density (5 moose per $\mathrm{km}^{2}$ ) (Fig. 2). For total abundance of soil mesofauna, the response was more linear, with a steady decrease along the gradient and significant differences between no simulated moose density and very high simulated density (Fig. 2b). Of the two numerically most important mesofauna groups, Collembola and Acarina respectively (Table 1), the total number of Collembola sampled per treatment area was highest at
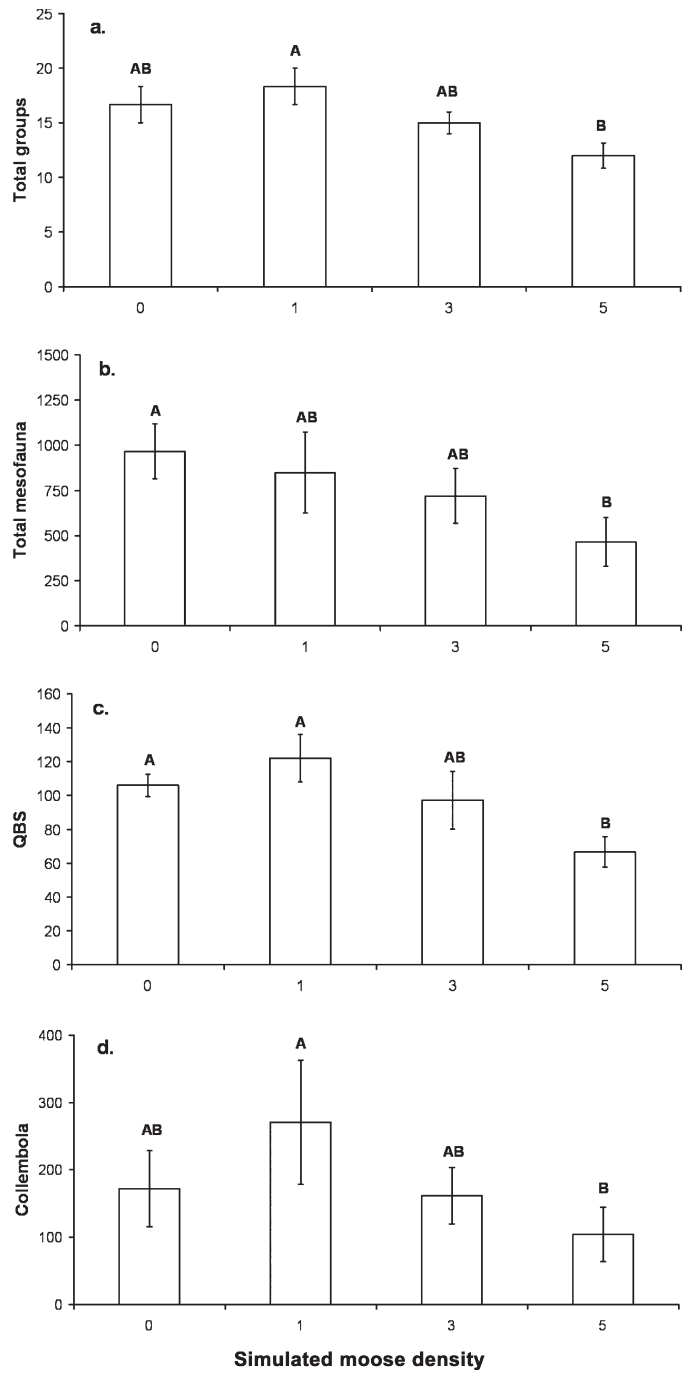

Fig. 2. The effect of different levels of simulated moose population density. $-a$. Total no. of eco-morphological groups, averaged over sites $(n=3)$. $-b$. Total no. of soil-living arthropods, averaged over sites. - c. Biological Soil Quality index (QBS). - d. Total no. of Collembola. Only variables showing significant $(p<$ 0.05 ) effects of simulated moose density are shown. Means and standard errors are presented. Different letters above the columns indicate that treatments are significantly different from each other at the $p<0.05$ level (Tukey test). Estimates of total mesofauna abundance and diversity are per volume soil sample $(3,000$ $\mathrm{cm}^{3}$ ).

low/moderate moose density and lowest in the very high density treatment (Fig. 2d). For total number of Acarina, there was no significant effect of treatment. However, both total number of 

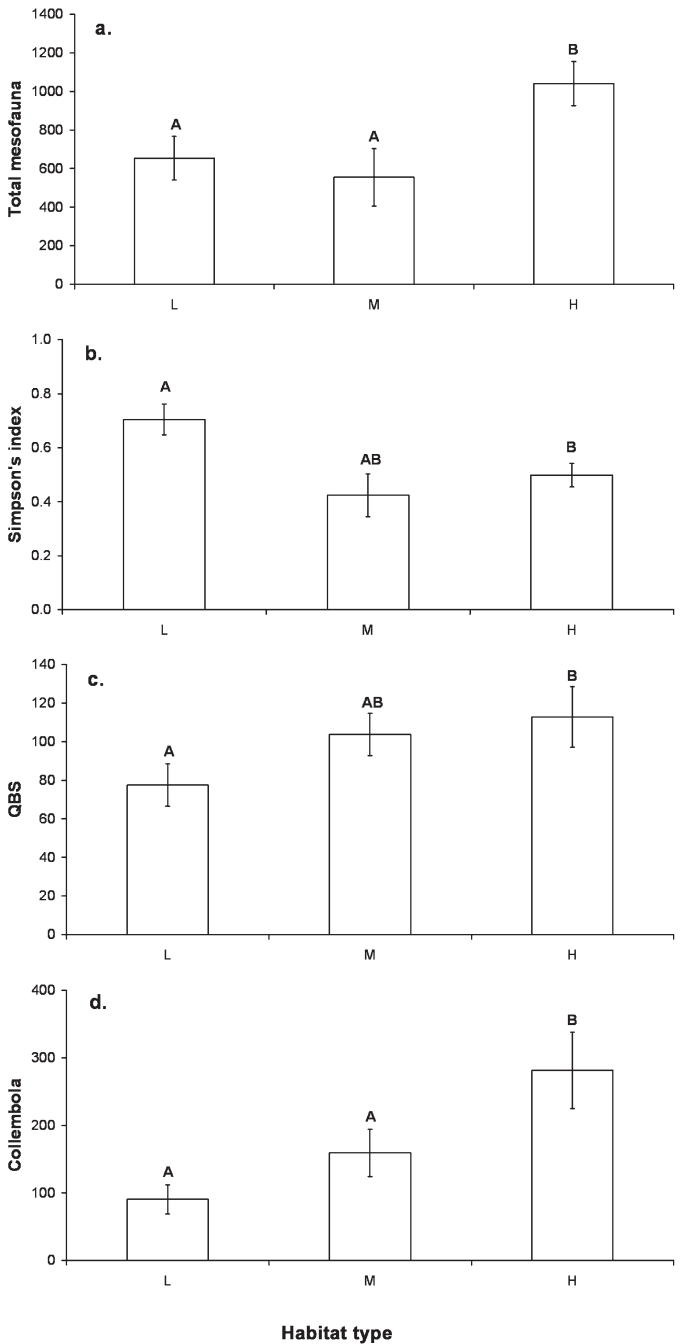

Fig. 3. The effect of habitat type, corresponding to different nutrient levels. $-a$. Total no. of soil-living arthropods. - b. Simpson index. - c. Biological Soil Quality index (QBS). - d. Total no. of Collembola. Means averaged over treatments $(n=4) . \mathrm{L}=$ low nutrient level, $\mathrm{M}=$ intermediate nutrient level, $\mathrm{H}=$ high nutrient level. Other details as in Fig. 2.

Collembola and Acarina showed a similar general pattern to the other measures, with the lowest number in the plots for which we had simulated a very high moose density (Fig. 2d, Table 1). ANOVA tests for diversity measured by the other biotic indexes found no significant effect of treatment on any index $\left(F_{3,6} \leq 2.39, p \geq 0.17\right)$.

Site effects were significant for total mesofauna abundance, total number of Collembola, the QBS (Table 2) and the Simpson index (F).
Values were higher in the high nutrient sites with the exception of the Simpson index, where sites with intermediate nutrient levels had the lowest diversity (Fig. 3). Differences approached significance ( $p=0.06-0.07)$ for total number of groups and total number of Acarina (Table 2), in each case the highest value being in the high nutrient site.

As shown in Fig. 4, there were positive linear relationships between litter production ( $\mathrm{g}$ dry mass per $\mathrm{m}^{2}$ per year) and total number of soil mesofauna $\left(F_{1,10}=16.70, p=0.003, r^{2}=0.63\right)$, total number of eco-morphological groups $\left(F_{1,10}=\right.$ $\left.7.43, p=0.02, r^{2}=0.43\right)$, the QBS index $\left(F_{1,10}=\right.$ $\left.6.82, p=0.026, r^{2}=0.41\right)$, total number of Collembola $\left(F_{1,10}=29.79, p<0.001, r^{2}=0.75\right)$ and total number of Acarina $\left(F_{1,10}=4.51, p=\right.$ $\left.0.059, r^{2}=0.31\right)$.

\section{Discussion}

Our results show that moose can indirectly have a significant impact on the abundance and number of eco-morphological groups of soil mesofauna, and on QBS index, in young boreal forest stands, and that the effect is strongly dependent on moose population density. The main conclusion is that, despite the wide range in habitat productivity, the effect of simulated moose browsing was consistent across the productivity gradient. There was also a general positive effect of nutrient level on mesofauna abundance and QBS as expected, although Simpson's index showed the lowest values at intermediate nutrient levels, possibly suggesting non-linear responses of certain diversity measures to productivity gradients.

The number of groups, the abundance of Collembola and QBS index all showed the highest value at low-moderate levels of moose population density indicating that moose at normal densities (around 1.0 moose per $\mathrm{km}^{2}$ for many areas in Sweden in winter) can actually have a positive effect on soil mesofauna in young boreal forest stands. However, at higher moose densities, corresponding to about 3 moose per $\mathrm{km}^{2}$ or more, moose can have a negative impact on soil arthropods. Densities of $2-3$ moose per $\mathrm{km}^{2}$ have occurred over large areas in Sweden (Cederlund \& Bergström 1996) and the local density (e.g. in 

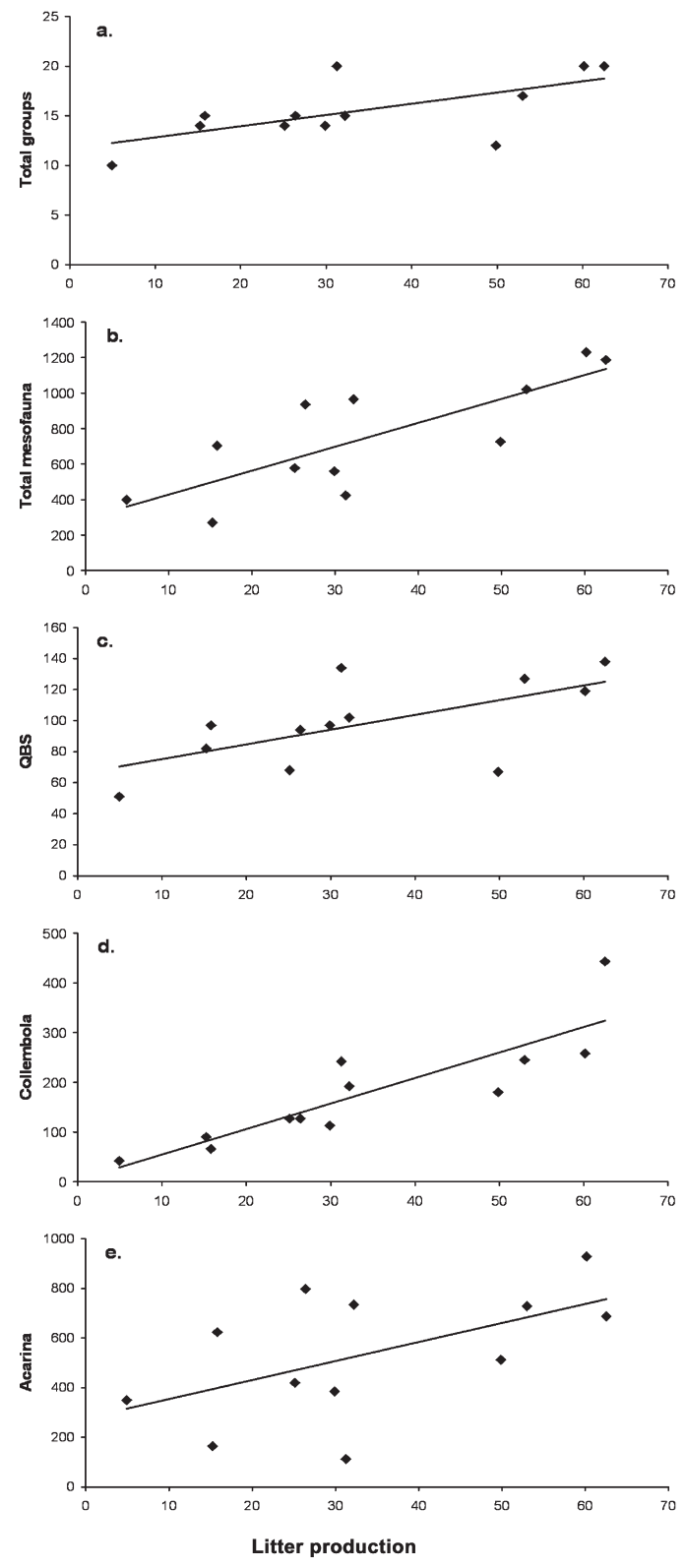

Fig. 4. Regressions between litter production ( $g$ dry mass per $\mathrm{m}^{2}$ per year) and soil variables. $-\mathrm{a}$. Total number of eco-morphological groups. - b. Total mesofauna abundance. - c. Biological Soil Quality index (QBS). - d. Total no. of Collembola. - e. Total no. of Acarina. Results of statistical tests are given in the text.

winter concentration areas) can be considerably higher (up to 5 moose per $\mathrm{km}^{2}$ or more). Although the general patterns in mean abundance in Acarina were similar to those for the number of groups, the abundance of Collembola and QBS index, suggesting some association with lower moose density sites (Table 1), treatment effects were not significant. This is probably due to the fact that we considered the abundance of all soildwelling Acarina sampled per treatment area (see below).

The QBS was formulated as an indicator of biological soil quality (Parisi et al. 2005). Whilst previous work has shown the QBS to be sensitive to broad land use and farming system, so far there is little evidence to suggest that the QBS is closely related to broader measures of soil quality such as pollution (Parisi et al. 2005) or organic carbon content (Gardi et al. 2002a). In this study, the QBS index proved to be a sensitive tool to estimate the simulated effects of moose density on soil mesofauna, showing significant differences when the other main diversity indices (ShannonWeaver, Menhinhick, Margalef and Simpson) failed to detect significant effects. In addition, the QBS showed significant associations with nutrient levels and a positive relationship with litter quantity. As there are also known negative impacts of high moose densities on wider aspects of soil quality from the same experimental set-up, namely $\mathrm{C}$ and $\mathrm{N}$ contributions (Persson et al. 2005a), we argue that these results suggest that the QBS may be a useful indicator of biological soil quality. Nevertheless, there may be some improvements that could be made in the components of the index, in particular Acarina are considered as a single group, thus pooling together a (probably high) number of species having high ecological diversity (Coleman et al. 2004), different feeding habits and using a wide range of ecological strategies (Vannier 1985, Lavelle \& Spain 2002). Further development of the QBS index should consider sub-division of some of the key groups, the Acarina in particular.

It is difficult to draw firm conclusions on the more general impact of moose on soil mesofauna with only one sampling period and limited number of samples. However, the fact that our results, despite the limited sampling and the large range in habitat productivity, showed significant effects on several variables strongly suggests that moose browsing is very likely to be an important factor determining pedofaunal communities in young boreal forest stands. The effects of moose at dif- 
ferent population densities on the soil mesofauna are likely to be caused by an indirect effect mediated by a chain of steps. The most important underlying mechanism is probably the effect of moose browsing on the growth of trees and shrubs and consequently on canopy structure and litter production (McInnes et al. 1992, Pastor \& Naiman 1992, Persson et al. 2005a, 2007).

The highest values in soil mesofauna abundance (mainly a result of the response in the dominant group Collembola), number of groups and the QBS index at low-moderate moose density might be explained by a slightly more open canopy increasing the amount of light reaching the forest floor and supporting more luxuriant herblayer vegetation (McInnes et al. 1992, Persson et al. 2007). Previous studies (e.g. Atlegrim \& Sjöberg 2003) indicate that the abundance of terricolous Collembola in boreal forests increases from shaded to more open forests. At the same time, the browsing pressure was probably too low to have any significant negative effects on annual litter production from the tree and shrub layers at low-moderate densities (Persson et al. 2005a). At higher moose densities, it is likely that the large decrease in litter production (Persson et al. 2005a) was a major explanation for the decrease in mesofauna abundance, number of groups and the QBS index, which is reflected in the significant positive correlations between litter and mesofaunal abundance and QBS (Fig. 4). Intense browsing substantially reduces both the amount of litter and nutrients returned to soil (Pastor \& Naiman 1992, Pastor et al. 1993, Persson et al. 2005a) which limits soil nutrient resources available for ground-dwelling fauna. The linear regressions showing positive effects of litter fall thus provide a strong indication that the effects of the simulated moose browsing on litter production were a main factor mediating the observed effects on the soil mesofauna. This confirms that, with respect to high moose densities, the limitation in soil nutrient resources caused by browsing and therefore litter reduction may have a stronger impact on soil mesofauna than the return in dung and urine (Pastor et al. 1993).

Collembola appeared to be more sensitive than other arthropods to moose impacts, showing a peak in abundance at moderate levels of moose density and low abundance at the highest densi- ties. Collembola populations probably benefitted at first from a higher rate of sunlight reaching the ground and the associated increased decomposition rate (Pastor et al. 1993, Augustine \& McNaughton 1998), thereafter decreasing when the impact of reduced litter production became greater than the positive effect of a more open canopy. Moreover, browsing by moose has been shown to have a significant negative effect on soil fungal communities and in particular on mycorrhizal infections of fine roots of preferred browse species (Rossow et al. 1997, Persson et al. 2000).

The fact that intense browsing substantially reduced the amount of leaf litter, likely also resulted in limited colonization by saprophytic fungi which are the most important decomposers in forest soils (Flanagan and Van Cleve 1983) and have been shown to be highly palatable to edaphic Collembola known to be primarily fungivorous (Fitter \& Sander 1992, Hopkin 1997, Rusek 1998, Jonas et al. 2007).

At the same time, it is likely that high browsing pressure decreased allocation of resources to root growth (Côte et al. 2004), and thus also had a negative impact on mycorrhizal fungi, which is another food source for Collembola (Setälä 1995, Jonas et al. 2007).

Since not only Collembola, but a range of soil invertebrates, feed on fungal spores and hyphae (Rabatin \& Stinner 1988, Shaw 1992, McGonigle 1997), we suggest that an indirect negative effect of intense browsing on soil fungi may have contributed to the pattern of mesofauna abundance by limiting their food sources. Thus, the negative impact on soil mesofauna at high moose densities might be due both to reduced litter fall and reduced presence of saprophytic and mycorrhizal fungi, although more studies are needed to separate the effects of these variables.

We are aware that moose can affect boreal ecosystems not only through their selective feeding, defecation and urination, but also through trampling, which has not been simulated in our experiment. Trampling certainly is a disturbance factor affecting composition of ground vegetation, development of fine roots, mineralization rates of nitrogen, soil compaction (Persson et al. 2000) and the movement of soil organisms through soil pore space (Wallwork 1970) and it is therefore likely to affect the diversity and density 
of soil mesofauna in forest soils, as demonstrated in the study carried out by Battigelli et al. (2004). However, research has shown that browsing and thus biomass loss is the most significant impact of moose in boreal forest ecosystems, and, considering the significant effects of decreased litter fall on several parameters, including vegetation richness and nutrient availability (Suominen et al. 2008, Persson et al., in press), it has been suggested that selective feeding affects the forest habitat more than trampling (Pastor \& Naiman 1992, Pastor et al. 1993, Suominen et al. 1999). Furthermore, the field work necessitated some (albeit light) trampling; the time spent in each treatment plot was in accordance with the different simulated moose densities. Further research on how moose trampling affects soil mesofauna in boreal forests is therefore needed, and will probably reveal complex effects and interactions with the other disturbance factors.

\section{Conclusions}

The importance of soil mesofauna for the integrity and functioning of terrestrial ecosystems is well recognised (Pankhurst 1997, BehanPelletier \& Newton 1999). Especially important is the role that soil fauna dynamics have on soil organic matter degradation in boreal acid soils (Kurcheva 1960). We thus conclude that moose density can be a major factor affecting soil-living arthropods, and consequently early stage decomposition of soil organic matter and biological soil quality in young boreal forest stands. However, it is clear that further research is needed to fully understand the processes involved. For moose management, and for conservation of biodiversity and fundamental ecosystem processes, our results strongly suggest that impact of large herbivores on soil invertebrates should be taken into account. This is particularly important as moose populations are increasing (Cederlund \& Bergström 1996) and densities in some areas are approaching those simulated in this experiment ( 5 individuals $/ \mathrm{km}^{2}$ ). Such high moose densities are likely to be detrimental to soil quality, and hence management to maintain moose densities to low-moderate levels, where effects on soils are beneficial, should be encouraged.
Acknowledgments. This study was financed by the Swedish Research Council for Environmental, Agricultural Sciences and Spatial Planning, the Swedish Environmental Protection Agency and the Forest Research Environment in Umeå (FORE). The forest companies Assi Domän / Sveaskog and Holmen Skog kindly allowed us to work on their land. We also thank two anonymous referees for their constructive comments.

\section{References}

Atlegrim, O. \& Sjöberg, K. 2003: Patterns of terricolous and field layer invertebrates along a boreal mire-forest ecotone. - Entomologia Fennica 14: 227-236.

Augustine, D. J. \& McNaughton, S. J. 1998: Ungulate effects on the functional species composition of plant communities: herbivore selectivity and plant tolerance. - Journal of Wildlife Management 6: 1165-1183.

Battigelli, J. P., Spence, J. R., Langor, D. W. \& Berch, S. M. 2004: Short-term impact of forest soil compaction and organic matter removal on soil mesofauna density and oribatid mite diversity. - Canadian Journal of Forest Research 34: 1136-1149.

Behan-Pelletier, V. \& Newton, G. 1999: Linking soil biodiversity and ecosystem function - the taxonomic dilemma. - BioScience 49: 149-153.

Bengtsson, J., Nilsson, S. G., Franc, A. \& Menozzi, P. 2000: Biodiversity, disturbances, ecosystem function and management of European forests. - Forest Ecology and Management 132: 39-50.

Bergström, R. \& Hjeljord, O. 1987: Moose and vegetation interactions in northwestern Europe and Poland. Swedish Wildlife Research Supplement 1: 213-227.

Blair, J. M. \& Crossley, D. A. 1988: Litter decomposition, nitrogen dynamics and litter microarthropods in a Southern Appalachian hardwood forest 8 years following clearcutting. - Journal of Applied Ecology 25: 683-698.

Cederlund, G., Ljungqvist, H., Markgren, G. \& Stålfelt, F. 1980: Foods of moose and roe deer at Grimsö in central Sweden - results of rumen content analyses. Swedish Wildlife Research 11: 169-247.

Cederlund, G. \& Bergström, R. 1996: Trends in the moose - forest system in Fennoscandia, with special reference to Sweden. - In: DeGraaf, R. M. \& Miller, R. I. (eds.), Conservation of Faunal Diversity in Forested Landscapes: 265-281. Chapman \& Hall, London.

Côte, S. D., Rooney, T. P., Tremblay, J.-P., Dussault, C. \& Waller, D. M. 2004: Ecological impacts of deer overabundance. - Annual Review of Ecology and Systematics 35: 113-147.

Coleman, D. C., Crossley, D. A. Jr. \& Hendrix, P. F. 2004: Fundamentals of soil ecology. Second edition. - Elsevier-Academic Press, Burlington, Massachusetts, USA.

Danell, K., Bergstrom, R. \& Edenius, L. 1994: Effects of large mammalian browsers on architecture, biomass and nutrients of woody plants. - Journal of Mamma- 
logy 75: 833-844.

Danell, K. Duncan, P., Bergstrom, R. \& Pastor, J. 2006: Large Herbivore Ecology, Ecosystem Dynamics and Conservation. - Cambridge University Press, Cambridge, $506 \mathrm{pp}$.

Eaton, R. J., Barbercheck, M., Buford, M. \& Smith, W. 2004: Effects of organic matter removal, soil compaction, and vegetation control on Collembolan populations. - Pedobiologia 48: 121-128.

Fitter, A. H. \& Sanders, I. R. 1992: Interactions with the soil fauna. - In: Allen, M.F. (ed.), Mycorrhizal functioning: an integrative plant-fungal process: $333-354$. Chapman \& Hall, New York.

Flanagan, P. W. \& Van Cleve, K. 1983: Nutrient cycling in relation to decomposition and organic-matter quality in taiga ecosystems. - Canadian Journal of Forest Research 13: 795-817.

Filser, J., Fromm, H., Nagel, R. F. \& Winter, K. 1995: Effects of previous intensive agricultural management on microorganisms and the biodiversity of soil fauna. — Plant and Soil 170: 123-129.

Gardi, C., Menta, C. \& Parisi, V. 2002a: Use of microarthropods as biological indicators of soil quality: The BSQ synthetic indicator. - In: Zdruli, P., Steduto, P. \& Kapur, S. (eds.), $7^{\text {th }}$ international meeting on soils with Mediterranean type of climate (selected papers): 297 304. Bari: CIHEAM-IAMB, 2002. Options Méditerranéennes, Série A, 50: 297-304.

Hobbs, N. T. 1996: Modification of ecosystems by ungulates. - Jounal of Wildlife Management 60: 695-712.

Hopkin, S. P. 1997: Biology of the springtails. — Oxford University Press, Oxford.

Jonas, J. L., Wilson, G. W. T., White, P. M. \& Joern, A. 2007: Consumption of mycorrhizal and saprophytic fungi by Collembola in grassland soils. - Soil Biology \& Biochemistry 39: 2594-2602.

Karlen, D. L., Mausbach, J. J., Doran, J. W., Cline, R. G., Harris, R. F. \& Schuman, G. E. 1997: Soil quality: a concept, definition, and framework for evaluation. Soil Science Society of America Journal 61: 4-10.

Kurcheva, G. F. 1960: The role of invertebrates in the decomposition of the oak leaf litter. - Pochvovedenie 4: 16-23.

Lavelle, P. \& Spain, A.V. 2002: Soil Ecology. - Kluwer Academic Publishers, Dordrecht.

Liiri, M., Setälä, H., Haimi, J., Pennanen, T. \& Fritze, H. 2002: Relationship between soil microarthropod species diversity and plant growth does not change when the system is disturbed. - Oikos 96: 137-149.

Magurran, A. E. 2004: Measuring Biological Diversity. Blackwell, Oxford.

Margalef, R. 1957: La teoria de la informacion en ecologia. - Memorias de la Real Academia de Ciencias y Artes de Barcelona. 32: 373-499; transl. by W. Hall, General Systems 3: 36-71.

McGonigle, T. P. 1997: Fungivores. - In: Wicklow, D. T. \& Söderström, B. E. (eds.), The Mycota IV: 237-248. Berlin, Springer-Verlag.

McInnes, P., Naiman, R. J. \& Pastor J. 1992: Effects of moose browsing on vegetation and litter of the boreal fo- rest, Isle Royale, Michigan, USA. - Ecology 73: 2059-2975.

Menhinick, E. P. 1964: A comparison of some species-individual diversity indices applies to samples of field insects. - Ecology 45: 859-861.

Moore, J. C. \& Walter, D. E. 1988: Arthropod regulation of micro- and mesobiota in below-ground detrital food webs. - Annual Review of Entomology 33: 419-439.

Nyberg, Å. \& Persson, I.-L. 2002: Habitat differences of coprophilous organisms on moose dung. - Mycological Research 106: 1360-1366.

Pankhurst, C. E. 1997: Biodiversity of soil organisms as an indicator of soil health. - In: Pankhurst, C. E., Doube, B. M. \& Gupta, V. V. S. R. (eds.), Biological Indicators of Soil Health: 297-324. CAB International, Wallingford.

Parisi, V. 2001: La qualità biologica del suolo. Un metodo basato sui microartropodi. - Acta Naturalia de "L'Ateneo Parmense" 37: 105-114. [In Italian.]

Parisi, V., Menta, C., Gardi, C., Jacomini, C. \& Mozzanica, E. 2005: Microarthropod communities as a tool to assess soil quality and biodiversity: a new approach in Italy. - Agriculture, Ecosystems and Environment 105: 323-333.

Pastor, J. \& Naiman, R. J. 1992: Selective foraging and ecosystem processes in boreal forests. - American Naturalist 139: 690-705.

Pastor, J., Dewey, B., Naiman, R.J., McInnes, P. F. \& Cohen, Y. 1993: Moose browsing and soil fertility in the boreal forests of Isle Royale National Park. - Ecology 74: 467-480.

Persson, I.-L., Danell, K. \& Bergström, R. 2000: Disturbance by large herbivores in boreal forests with special reference to moose. - Annales Zoologici Fennici 37: 251-263.

Persson, I.-L. 2003: Moose population density and habitat productivity as drivers of ecosystem processes in northern boreal forests. - PhD Thesis, Swedish University of Agricultural Sciences, Umeå, Sweden.

Persson, I.-L., Pastor, J., Danell, K. \& Bergström, R. 2005a: Impact of moose population density on the production and composition of litter in boreal forests. Oikos 108: 297-306.

Persson, I.-L., Danell, K. \& Bergström, R. 2005b: Different moose densities and accompanied changes in tree morphology and browse production. - Ecological Applications 15: 1296-1305.

Persson, I.-L., Bergström, R. \& Danell, K. 2007: Browse biomass production and regrowth capacity after biomass loss in deciduous and coniferous trees: responses to moose browsing along a productivity gradient. Oikos 116: 1639-1650.

Persson, I.-L.,Nilsson, M.B., Pastor, J., Eriksson, T., Bergström, R. \& Danell, K. 2009: Depression of belowground respiration rates at high moose population densities in boreal forests. - Ecology 90: 2724-33.

Ponge, J. F., Gillet, S., Dubs, F., Fedoroff, E., Haese, L., Sousa, J. P. \& Lavelle, P. 2003: Collembolan communities as bioindicators of land use intensification. Soil Biology \& Biochemistry 35: 813-826. 
Rabatin, S. C. \& Stinner, B. R. 1988: Indirect effects of interaction between VAM fungi and soil-inhabiting invertebrates on plant processes. - Agriculture, Ecosystems and Environment 24: 135-146.

Rossow, L. J., Bryant, J. P. \& Kielland, K. 1997: Effects of above-ground browsing by mammals on mycorrizhal infection in an early successional taiga ecosystem. Oecologia 110: 94-98.

Rusek, J. 1998: Biodiversity of Collembola and their functional role in the ecosystem. - Biodiversity and Conservation 7: 1207-1219.

Sacchi, C. F. \& Testard, P. 1971: Ecologie Animale. Doin, Paris. [In French.]

Seasted, T. R. 1984: The role of microarthropods in decomposition and mineralization processes. - Annual Review of Entomology 29: 25-46.

Shannon, C. E. \& Weaver, W. 1948: The Mathematical Theory of Communication. - University of Illinois Press, Urbana. 144pp.

Shaw, P. J. A. 1992: Fungi, fungivores and fungal webs. In: Carrol, G. C. \& Wicklow, D. T. (eds.), The fungal community: its organization and role in the ecosystem: 295-310. New York, Marcel Dekker.

Simpson, E. H. 1949: Measurement of diversity. — Nature 163: 688.

Stork, N. E. \& Eggleton, P. 1992: Invertebrates as determinants and indicators of soil quality. - American Journal of Alternative Agriculture 7: 38-47.

Setälä, H. 1995: Growth of birch and pine seedlings in relation to grazing by soil fauna on ectomycorrhizal fungi. — Ecology 76: 1844-1851.

Suominen, O., Danell, K. \& Bergström, R. 1999: Moose, trees, and ground-living invertebrates: indirect interactions in Swedish pine forests. - Oikos 84: 215226.
Suominen, O., Persson I.-L., Danell, K., Bergström, R. \& Pastor, J. 2008: Impact of simulated moose densities on abundance and richness of vegetation, herbivorous and predatory arthropods along a productivity gradient. - Ecography 31: 636-645.

Takeda, H. 1987: Dynamics and maintenance of Collembolan community structure in a forest soil ecosystem. — Researches on Population Ecology 29: 291-346.

Van der Wal, R., Bardgett, R. D., Harrison, R. D. \& Stien, A. 2004: Vertebrate herbivores and ecosystem control: cascading effects of faeces on tundra ecosystem. Ecography 27: 242-252.

Van Straalen, N. M. 1997: Community structure of soil arthropods as a bioindicator of soil health. - In: Pankhurst, C. E., Doube, B. M. \& Gupta, V. V. S. R. (eds.), Biological Indicators of Soil Health: 235-264. CAB International, Wallingford.

Vannier, G. 1985: Modes d'exploitation et partage des ressources alimentaires darts le systeme saprophage par les microarthropodes du sol. — Bulletin d'Ecologie 16: 19-34.

Wallwork, J. A. 1970: Ecology of soil animals. McGraw-Hill, London.

Wardle, D. A., Nicholson, K. S., Bonner, K. I. \& Yeates, G. W. 1999: Effects of agricultural intensification on soilassociated arthropod population dynamics, community structure, diversity and temporal variability over a seven-year period. - Soil Biology \& Biochemistry 31: 1691-1706.

Wardle, D. A., Barker, G. M., Yeates, G. W., Bonner, K. I. \& Ghani, A. 2001: Introduced browsing mammals in New Zealand natural forests: Aboveground and belowground consequences. - Ecological Monographs 71: 587-614. 